\title{
Genetic Diversity of Local Greek and Bulgarian Grapevine (Vitis Vinifera L.) Varieties
}

\author{
Maria Papapetrou ${ }^{1}$, Dimitrios Loukovitis ${ }^{1,2, * \mathbb{C}}$, Orestis Papadopoulos ${ }^{1}$, Zoi Kazlari ${ }^{1}$, \\ Anastasia Peristeraki ${ }^{1}$, Slavina Arsenova ${ }^{3}$, Desislava Bardarova ${ }^{3}$, Desislava Doncheva ${ }^{3}$, \\ Serafeim Theocharis ${ }^{4}$, Constantinos Karagiannidis ${ }^{1}$, Stefanos Koundouras ${ }^{4}$, \\ Anastasia Giannakoula ${ }^{1}$, Stamatis Aggelopoulos ${ }^{1}$ and Dimitrios Chatziplis ${ }^{1}$ \\ 1 Department of Agriculture, International Hellenic University, 57400 Sindos, Thessaloniki, Greece; \\ papapetrmaria@gmail.com (M.P.); p.orestisjim@yahoo.gr (O.P.); zoikaz@hotmail.gr (Z.K.); \\ natasa595@gmail.com (A.P.); konstantin.karagian@gmail.com (C.K.); agianna@cp.teithe.gr (A.G.); \\ stamagg40@gmail.com (S.A.); chatz@ap.teithe.gr (D.C.) \\ 2 Research Institute of Animal Science, ELGO Demeter, 58100 Paralimni, Giannitsa, Greece \\ 3 Association Prosperity and Development in Bulgaria, 2700 Blagoevgrad, Bulgaria; \\ s.k.arsenova@gmail.com (S.A.); pdbulgaria2010@gmail.com (D.B.); doncheva@bccid.com (D.D.) \\ 4 School of Agriculture, Aristotle University of Thessaloniki, 54124 Thessaloniki, Greece; \\ sertheo@agro.auth.gr (S.T.); skoundou@agro.auth.gr (S.K.) \\ * Correspondence: dloukovi@hotmail.com
}

Received: 29 May 2020; Accepted: 3 July 2020; Published: 9 July 2020

\begin{abstract}
The aim of this study was to estimate the genetic diversity of Greek and Bulgarian grapevine varieties with the use of microsatellite markers. The studied samples were collected from various productive vineyards, consisting of eight Greek and nine Bulgarian native varieties. In order to create a genetic profile for each sample, a multiplex PCR reaction method was used amplifying simultaneously seven microsatellite loci. Statistical analysis of data showed that there was a high degree of genetic heterogeneity among most of the varieties studied, highlighting the discriminative power of the chosen set of markers. Moreover, the synonymy of (I) Greek Pamid and Bulgarian Pamid and (II) Greek Zoumiatiko and Bulgarian Dimyat was suggested, as each variety pair had identical allele profiles in all loci examined. Regarding the Greek Mavrud and Bulgarian Mavrud varieties, there was a close genetic relationship between them, however, they did not share common alleles in all microsatellite loci and, therefore, should not be characterized as synonyms. On the other hand, Greek and Bulgarian Keratsouda, which were supposed to be common varieties, were found to be genetically different, supporting that these two varieties should be considered as homonyms. Despite the genotypic assay performed herein, we believe that additional molecular work is needed for the efficient management of Greek and Bulgarian grapevine genepools, as well as to safely suggest any synonym or homonym annotation.
\end{abstract}

Keywords: grapevine; genetic diversity; microsatellite markers; differentiation; Vitis vinifera

\section{Introduction}

Grapevine (Vitis Vinifera L.) is a major fruit tree widespread in temperate climates, which has been cultivated for more than 5000 years to produce wine and for consumption directly as a grape [1]. In Greece, grapevine has been cultivated since antiquity [2] and ampelographic collection accounts for 663 single cultivars, 300 of which are still cultivated for wine, table grapes and raisins [3]. Grapevine cultivation and winemaking in Bulgaria dates back to the times of ancient Thrace and, nowadays, the commercial varieties consist of old native varieties, widespread European cultivars and locally selected cultivars [4]. 
Greece and Bulgaria are neighboring countries and there has been an extensive exchange of $V$. vinifera germplasm for cultivation, mostly in the areas near the borders. This has resulted in the establishment of Greek and Bulgarian local varieties with similar morphological characteristics, called "common". However, in order to confirm or reject any suspected synonymy between varieties coming from these two countries, ampelographic data should be evaluated along with molecular genetic data.

The existence of diverse geographical and climate conditions in the above two countries resulted in a range of local varieties that have been completely adapted to the local conditions, possessing unique properties for winemaking. These varieties have been somehow abandoned during the last decades and gradually replaced by international varieties, mostly due to their higher performance [5]. However, the neglected traditional varieties represent valuable genetic resources that can provide the material for making products with novel characteristics, which could be successfully promoted into international markets. The initial step towards this direction should be the precise characterization of the local grapevine genepool, using molecular methods, in combination with ampelographic data.

Simple sequence repeats (SSR) or short tandem repeats (STR) markers, also known as microsatellites, have been widely used since the early 1990s [6] and are nowadays considered to be some of the best methods for determining cultivar identity. Due to their high polymorphism, microsatellite markers have significantly improved the robustness of DNA profiling in parentage analysis [7-11] and in the molecular characterization of grape cultivars [12-21].

The aim of this study was to analyze the genetic diversity and differentiation of various local Greek and Bulgarian grapevine varieties, using microsatellite genetic markers. Besides that, our goal was also to clarify the putative relationship of varieties coming from the above two countries and characterized as common.

\section{Materials and Methods}

\subsection{Sampling, DNA Extraction and Genotyping}

Young leaves were collected from several locations in Bulgaria and Greece (Table S1, Figure S1) [22] and immediately stored in a freezer $\left(-20^{\circ} \mathrm{C}\right)$ until further analysis. In total, 384 samples were collected from both countries. Genomic DNA was extracted from 20-30 mg of leaf tissue using the "NucleoSpin Plant II" DNA extraction kit (Macherey-Nagel, Düren, Germany) and according to the manufacturer's protocol.

The multiplex PCR reaction method amplifying simultaneously seven microsatellite loci was carried out. Six of the selected microsatellites are included in the nine-SSR panel recommended by the International Organization of Vine and Wine for identification of varieties (OIV 2019 Descriptor List for Grape Varieties and Vitis Species). The seventh chosen marker is a commonly used marker in grapevine DNA profiling [4,12]. All multiplex PCRs were performed in $10 \mu \mathrm{L}$ volume containing $5.5 \mu \mathrm{L}$ of $1 \mathrm{X}$ KAPA2G Fast Multiplex PCR Kit (KAPABIOSYSTEMS, Wilmington, MA, USA), $3.5 \mu \mathrm{L}$ of primer mix $(0.25 \mu \mathrm{M}$ for each primer) and $1 \mu \mathrm{L}(\sim 20 \mathrm{ng})$ of template DNA. Cycling conditions for the multiplex amplification consisted of an initial $95^{\circ} \mathrm{C}$ denaturation step for $3 \mathrm{~min}$ followed by 30 cycles of $15 \mathrm{~s}$ at $95^{\circ} \mathrm{C}, 30 \mathrm{~s}$ at $56^{\circ} \mathrm{C}$ and $30 \mathrm{~s}$ at $72{ }^{\circ} \mathrm{C}$, with a final extension at $72{ }^{\circ} \mathrm{C}$ for $15 \mathrm{~min}$. Fluorescently labeled PCR products were separated on an ABI 3500 Genetic Analyzer (Applied Biosystems, Foster City, CA, USA). Alleles were sized and samples genotyped using the STRand 2.4.59 software [23]. Detailed information for microsatellite markers is given in Table S2 [6-8,24,25].

\subsection{Data Analysis}

Regarding Bulgarian samples, we defined populations based on producer, location and variety information. As a consequence, we had (in some cases) populations belonging to the same variety but coming from different producers and sampling areas (locations). For example, we had a Tamyanka variety from BRATANOV WINERY (producer) and Shishmanovo (location) but we also had a Tamyanka variety from DIMITAR DJEMPERLIEV (producer) and Dimitrovche (location). These were treated 
initially as two different populations. However, according to preliminary results (Table S3), we noticed that all populations of the same variety were genetically similar (statistically undifferentiated) to each other, regardless of the producer and location of each population. This scenario was evident (with no exception) for all the Bulgarian varieties studied herein. Therefore, we redefined populations based exclusively on variety information (Table S4).

Genetic variation parameters (number of alleles $(A)$, observed $\left(H_{o}\right)$ and expected $\left(H_{e}\right)$ heterozygosity, F-statistics fixation indexes (WeIr and CоскеRнам [26])) were calculated using the FSTAT 2.9.3.2 and GENETIX 4.05.2 statistical packages [27,28]. The FSTAT software was also used to test for statistically significant differentiation between all possible pairs of the studied populations. A $p$-value for each pair was obtained after 136,000 permutations and the significance of the pairwise tests was checked after standard Bonferroni correction.

Graphic dispersion of varieties was carried out using factorial correspondence analysis (FCA) through GENETIX 4.05.2. Finally, the POPTREEW [29] package was used to construct an unweighted pair group method with arithmetic mean (UPGMA) dendrogram based on Nei's standard genetic distance with sample size bias correction [30]. Assessment of support for clusters on the tree was performed through 1000 bootstrap resamplings of loci.

\section{Results and Discussion}

\subsection{Genetic Variation}

In total, 53 different alleles were found in the 384 samples analyzed with seven microsatellite loci. The polymorphism of the markers was low to medium, ranging from 4 (VvMD25) to 10 (VrZAG79) alleles, with a mean of 7.6 (Table S2) $[6-8,24,25]$. The Mishej Sandanski variety exhibited the highest mean number of alleles (4.71), while the lowest respective value was found in the $\operatorname{Keratsouda}(G)$ variety (1.57) (Table 1). The mean number of alleles per locus was lower than those reported by LeforT and Roubelakis-Angelakis [12], Hvarleva et al. [4] and Sefc et al. [31] for the common loci among studies, which can be attributed to the higher number of germplasm collections analyzed by the previous two studies.

The population $H_{0}$ values ranged from 0.57 to 1 with a mean of 0.79 , while the respective range for $H_{e}$ was much lower $(0.3$ to 0.6$)$ and averaged 0.45 , indicating a heterozygote excess in our data. This is also supported by the mean (across loci and populations) $F_{i s}$ and $F_{i t}$ values ( -0.78 and -0.036 , respectively) as well as by the population $F_{i s}$ values that were, in all cases, significantly different from zero (Table 1). According to SEFC et al. [31], the selection for highly heterozygous plants has been intensified in the frame of domestication and cultivation of grapevines, when the genotypes were evaluated based on their agronomic performance. In addition, selfing (self-pollination) of grapevines decreases heterozygosity which may lead to inbreeding depression and/or occurrence of deleterious recessive traits. The excess of heterozygosity observed herein might be a consequence of both natural and artificial (human) selection against homozygosity in grape plants.

Finally, Hvarleva et al. [4], Lefort and Roubelakis-Angelakis [12] and Merkouropoulos et al. [17] reported $H_{o}$ values of $0.77,0.82$ and 0.79 , respectively, when analyzing Greek and/or Bulgarian cultivars, which are somewhat similar to the mean $H_{0}$ value found herein $(0.79)$. 
Table 1. Number of alleles $(A)$, observed heterozygosity $\left(H_{0}\right)$, expected heterozygosity $\left(H_{\mathcal{e}}\right)$ and inbreeding coefficient $\left(F_{i s}\right)$ (across all microsatellite loci) for populations under study.

\begin{tabular}{|c|c|c|c|c|}
\hline Variety & $A$ & $H_{o}$ & $H_{e}$ & $F_{i s}$ \\
\hline $\operatorname{Pamid}(\mathrm{G})$ (also known as 'Pamidi') & 3.0000 & 0.7347 & 0.4252 & -0.7780 * \\
\hline Keratsouda $(G)$ & 1.5714 & 0.5714 & 0.3008 & $-0.6915 *$ \\
\hline Zoumiatiko & 1.8571 & 0.8571 & 0.4511 & -0.9080 * \\
\hline Limnio & 1.8571 & 0.8571 & 0.4511 & -0.9080 * \\
\hline Sefka & 1.8571 & 0.8571 & 0.4511 & $-0.9080 *$ \\
\hline Mavrud(G) (also known as 'Mavroudi') & 2.1429 & 1.0000 & 0.5481 & -0.9440 * \\
\hline Bogialamas & 2.0000 & 0.7143 & 0.3931 & -0.7638 * \\
\hline Karnachalas & 2.0000 & 1.0000 & 0.5238 & -0.9775 * \\
\hline Tamyanka & 4.5714 & 0.8736 & 0.5930 & -0.4880 * \\
\hline Mavrud(B) & 4.1429 & 0.9725 & 0.5952 & -0.6550 * \\
\hline Rubin & 2.2857 & 0.8500 & 0.4533 & -0.9190 * \\
\hline Pamid(B) & 2.8571 & 0.7143 & 0.4726 & -0.5690 * \\
\hline Dimyat & 1.8571 & 0.8571 & 0.4403 & -0.9325 * \\
\hline Ruen & 1.8571 & 0.7214 & 0.3734 & -0.9800 * \\
\hline Shizoka Melnishkaloza & 2.7143 & 0.5807 & 0.3258 & -0.8020 * \\
\hline Mishej Sandanski & 4.7143 & 0.6554 & 0.4835 & -0.3650 * \\
\hline Keratsouda(B) & 4.5714 & 0.5946 & 0.3580 & -0.6660 * \\
\hline Mean & 2.6975 & 0.7889 & 0.4494 & -0.7797 \\
\hline
\end{tabular}

\subsection{Genetic Differentiation}

Average $F_{S T}$ over loci and samples was 0.41 , showing that nearly half of the genetic diversity is explained between populations. According to the pairwise multilocus $F_{S T}$ estimates (Table S5), the lowest values were observed between Pamid(G) and Pamid(B) (-0.0040), Zoumiatiko and Dimyat (0.0000) and Mavrud(G) and Mavrud(B) (0.0175), being statistically non-different from zero. All other $F_{S T}$ values were quite high, ranging from 0.1835 to 0.6154 , indicating that there is a high level of genetic differentiation between the remaining varieties. This finding is also supported by the population differentiation analysis through the FSTAT software, where all population pairs were found statistically different (at least at a $1 \%$ level of significance), except for the aforementioned three variety pairs that were not significantly different (Table S6). Biniari and StAVRaKaKi [32] and Merkouropoulos et al. [17] also reported a high degree of genetic heterogeneity when analyzing the same Greek varieties with random amplified polymorphic DNA (RAPD) and microsatellite markers. Finally, significant genetic differentiation was found for the Dimyat, Mavrud(B), Pamid(B), Tamyanka, Mishej Sandanski and Rubin varieties by HvarLeva et al. [4], with the use of SSR markers.

According to the factorial correspondence analysis (Figure 1a), there is an obvious genetic similarity for the Zoumiatiko and Dimyat and Pamid(G) and Pamid(B) variety pairs. Mavrud(G) and Mavrud(B) are also close to each other, though to a lower degree. On the other hand, Sefka, Limnio, Karnachalas, Bogialamas, Rubin and Tamyanka populations tend to isolate more compared with all the others. The UPGMA tree topology, comprised of two major clusters (I and II, Figure 1b), verified with high bootstrap values the close relationship of the three undifferentiated variety pairs mentioned previously. Cluster I includes three Greek and three Bulgarian populations. Cluster II is further divided in two subclusters of equal size to cluster I, with the first one containing a Bulgarian variety (Mavrud(B)) and all the rest Greek varieties, while the second one includes the remaining Bulgarian populations. The differentiation patterns observed in the FCA plot and the UPGMA dendrogram are, with minor exceptions, in agreement with the pairwise $F_{S T}$ estimates and the population differentiation analysis of the studied varieties. 


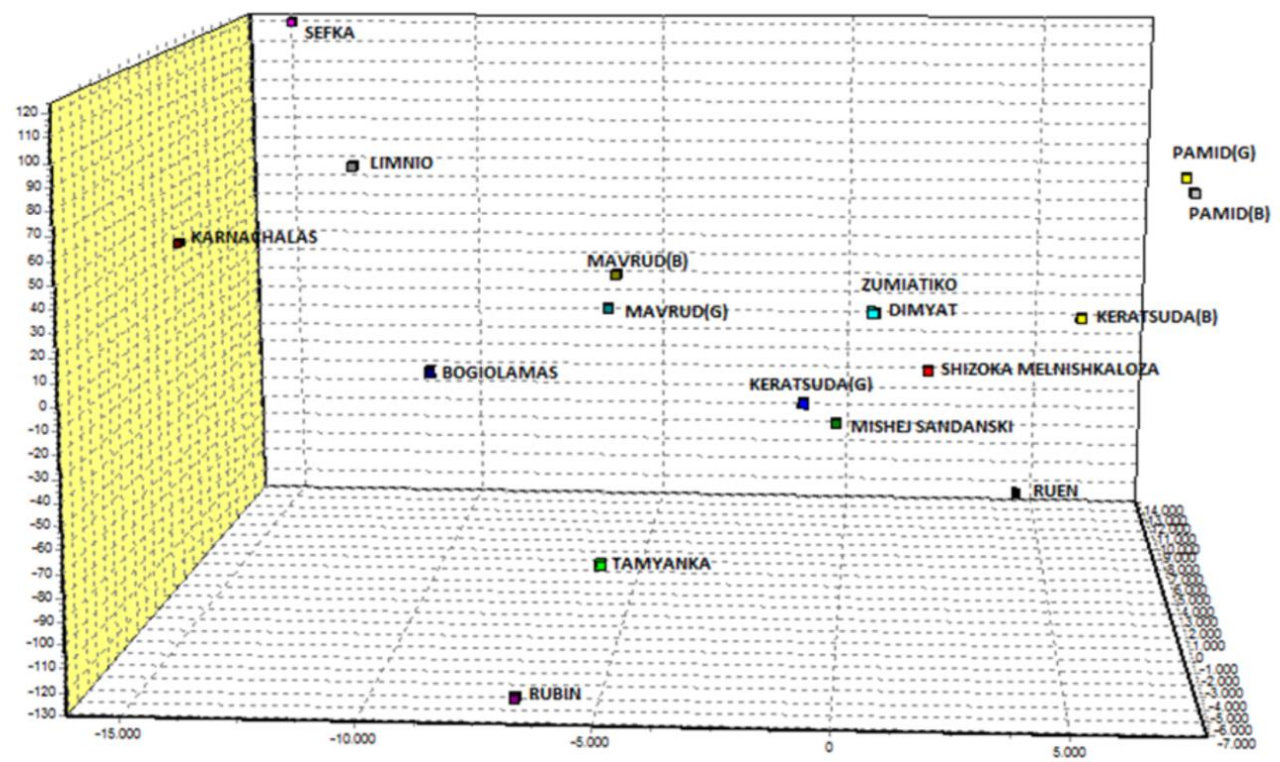

(a)

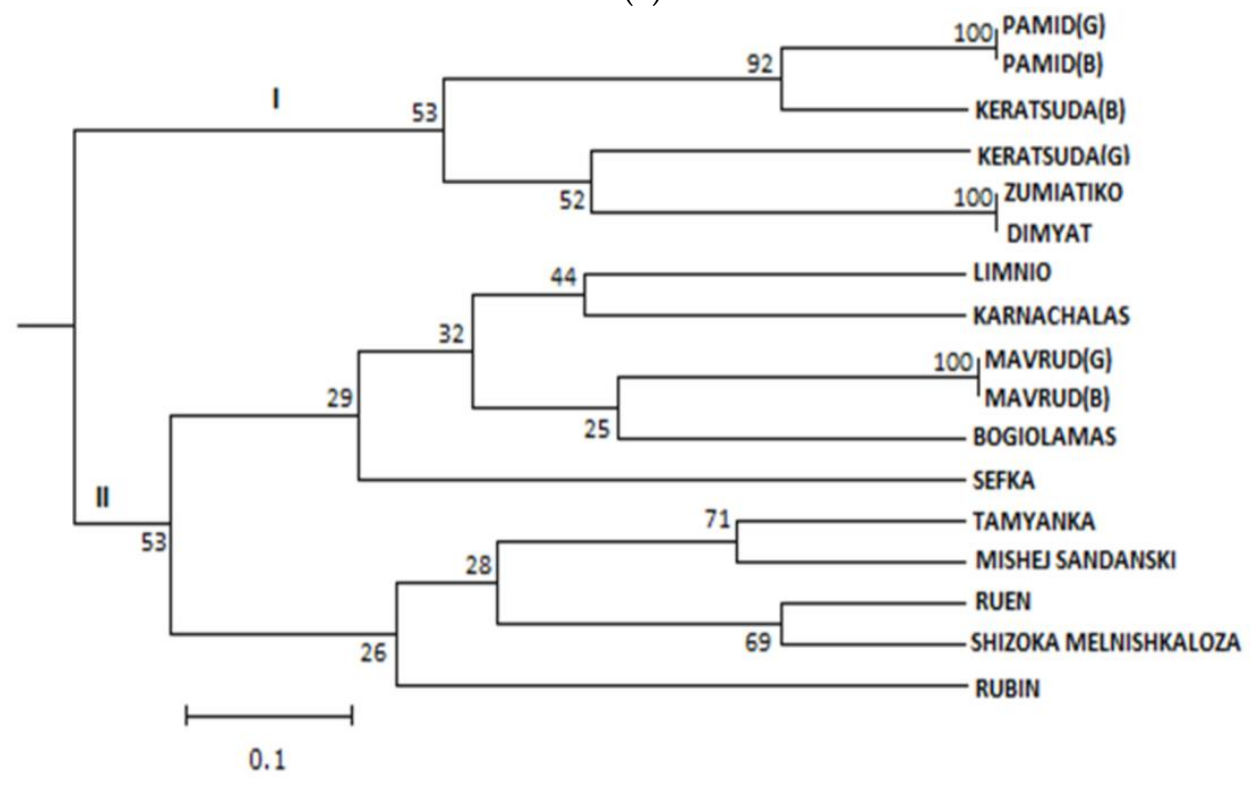

(b)

Figure 1. Factorial correspondence analysis of all Greek and Bulgarian grapevine varieties under study, using the Genetix 4.05.2 software (a); unweighted pair group method with arithmetic mean (UPGMA) dendrogram of all studied varieties constructed with the POPTREEW package, comprised of two major clusters (I and II). Numbers in nodes represent bootstrap values (b).

The genetic similarity of the variety pairs Zoumiatiko and Dimyat, Pamid(G) and Pamid(B) and Mavrud(G) and Mavrud(B) is supported by all methods of statistical analysis conducted in the present study. Looking at their genotypes, the Zoumiatiko and Dimyat varieties have identical alleles in all loci examined and, therefore, we suggest them to be considered as synonyms. The same goes for $\operatorname{Pamid}(G)$ and Pamid(B) populations, which is also reported in HvarLeva et al. [4], where Bulgarian and Greek Pamid were found to be synonyms, having identical allele profiles. Regarding the Mavrud(G) and Mavrud(B) varieties, there is a close genetic relationship between them, however, they do not share common alleles in all microsatellite loci and should not be characterized as synonyms. This finding verifies the results of Hvarleva et al. [4] and StavraKaKi and Biniari [33], where it was demonstrated that native Bulgarian Mavrud is a homonym to Greek Mavrud despite their genetic homogeneity. 
Finally, Keratsouda $(\mathrm{G})$ and Keratsouda(B), which are suspected to be synonyms, are in fact different (1\%o level of significance) with a quite high $F_{S T}$ value (0.4266), while their genotypes differ in all seven examined loci. In that case, we propose that these two varieties should be considered as homonyms.

\section{Conclusions}

From our point of view, the evaluation and promotion of traditional grapevine varieties from Greece and Bulgaria are urgent as they constitute native cultivars that demonstrate excellent adaptation to the microenvironment, favoring as well an environmentally friendly agricultural system of low inputs. These neglected varieties could provide the material for making wine products with exceptional characteristics and, subsequently, high economic value. Our study showed that Greek and Bulgarian local varieties form distinct genepools, with the exception of three pairs (Zoumiatiko and Dimyat, $\operatorname{Pamid}(G)$ and Pamid(B) and Mavrud(G) and Mavrud(B)) that were found to be genetically related. Despite the discriminative power of the chosen set of microsatellites, we strongly believe that additional work is needed with more varieties and representatives of them analyzed with a higher number of molecular markers. This, in combination with ampelographic description and historical data, will provide us with the reliable tools needed for accurate identification and discrimination of these valuable genetic resources, as well as for confirming or invalidating any supposed synonymy or homonymy among them.

Supplementary Materials: The following are available online at http://www.mdpi.com/1424-2818/12/7/273/s1, Figure S1. Map showing Greek and Bulgarian collection sites of grapevine samples [22]. Sites are numbered according to Table S1, Table S1. Locations and varieties of collected samples in Greece and Bulgaria, Table S2. Information for used microsatellite markers $[6-8,24,25]$, Table S3. Pairwise $F_{S T}$ values among Bulgarian populations. Each color represents populations of the same variety (different for each variety), coming from different producers and sampling areas. All populations of the same variety are statistically undifferentiated (pairwise tests of differentiation in FSTAT software), with their $F_{S T}$ values being non-different from zero $(p<0.05)$. This scenario is evident, with no exception, for all the Bulgarian varieties studied, Table S4. Greek (1-8) and Bulgarian (9-17) populations-varieties used in the present study. Letters $\mathrm{G}$ and B in parentheses stand for Greek and Bulgarian, respectively, Table S5. Pairwise $F_{S T}$ values between all possible pairs of the studied populations, Table S6. Population differentiation analysis implemented in FSTAT 2.9.3.2 software.

Author Contributions: Conceptualization, S.A. (Stamatis Aggelopoulos); data curation, S.A. (Stamatis Aggelopoulos); formal analysis M.P. and D.L.; funding acquisition S.A. (Stamatis Aggelopoulos); investigation, M.P., D.L., O.P., Z.K., A.P., methodology, M.P. and D.L.; project administration, D.D., S.K., A.G., S.A. (Stamatis Aggelopoulos), D.C.; resources, S.A. (Slavina Arsenova), D.B., D.D., S.T., C.K., S.K., S.A. (Stamatis Aggelopoulos); software, M.P. and D.L.; supervision, D.D., S.K., A.G., S.A. (Stamatis Aggelopoulos), D.C.; validation, M.P. and D.L.; visualization, M.P. and D.L.; writing—original draft, M.P. and D.L.; writing—review and editing, all authors. All authors have read and agreed to the published version of the manuscript.

Funding: This research was funded by the European Regional Development Fund (ERDF) and national funds of Greece and Bulgaria through the Cooperation Programme INTERREG V-A “Greece-Bulgaria 2014-2020", Research Project: "SOS for endangered traditional vine varieties—VineSOS" (Project Number MIS: 5016071).

Conflicts of Interest: The authors declare no conflict of interest.

\section{References}

1. Olmo, H.P. Grapes. In Evolution of Crop Plants; Simmonds, N.W., Ed.; Longman: London, UK, 1976; pp. 294-298.

2. Banilas, G.; Korkas, E.; Kaldis, P.; Hatzopoulos, P. Olive and grapevine biodiversity in Greece and Cyprus-a review. In Climate Change, Intercropping, Pest Control and Beneficial Microorganisms; Lichtfouse, E., Ed.; Springer: Berlin, Germany, 2009; pp. 401-428.

3. Kotinis, X. Ampelographic Atlas of Greece (in Greek with French Summary). Athens. 1985. Available online: http://gvd.biology.uoc.gr/gvd/ (accessed on 16 March 2020).

4. Hvarleva, T.; Rusanov, K.; Lefort, F.; Tsvetkov, I.; Atanassov, A.; Atanassov, I. Genotyping of Bulgarian Vitis vinifera L. cultivars by microsatellite analysis. Vitis 2004, 43, 27-34.

5. This, P.; Lacombe, T.; Thomas, M.R. Historical origins and genetic diversity of wine grapes. Trends Genet. 2006, 22, 511-519. [CrossRef] 
6. Thomas, M.R.; Scott, N.S. Microsatellite repeats in grapevine reveal DNA polymorphisms when analysed as sequence-tagged sites (STSs). Theor. Appl. Genet. 1993, 86, 985-990. [CrossRef] [PubMed]

7. Bowers, J.; Dangl, G.; Vignani, R.; Meredith, C. Isolation and characterization of new polymorphic simple sequence repeat loci in grape (Vitis vinifera L.). Genome 1996, 39, 628-633. [CrossRef] [PubMed]

8. Bowers, J.; Dangl, G.; Meredith, C. Development and characterization of additional microsatellite DNA markers for grape. Am. J. Enol. Vitic. 1999, 50, 243-246.

9. Laucou, V.; Boursiquot, J.M.; Lacombe, T.; Bordenave, L.; Decroocq, S.; Ollat, N. Parentage of grapevine rootstock 'Fercal' finally elucidated. Vitis 2008, 47, 163-167.

10. Štajner, N.; Tomić, L.; Progar, V.; Pokorn, T.; Lacombe, T.; Laucou, V.; Boursiquot, J.M.; Javornik, B.; Bacilier, R. Genetic clustering and parentage analysis of Western Balkan grapevines (Vitis vinifera L.). Vitis 2015, 54, 67-72.

11. Biagini, B.; Imazio, S.; Scienza, A.; Failla, O.; de Lorenzis, G. Renewal of wild grapevine (Vitis vinifera L. subsp. sylvestris (Gmelin) Hegi) populations through sexual pathway: Some Italian case studies. Flora 2016, 219, 85-93. [CrossRef]

12. Lefort, F.; Roubelakis-Angelakis, K. Assessing the identity of grapevine plants from vineyards from Crete and Samos by microsatellite profiling. OENO One 2002, 36, 177-183. [CrossRef]

13. Martin, J.P.; Borrego, J.; Cabello, F.; Ortiz, J.M. Characterization of Spanish grapevine cultivar diversity using sequence-tagged microsatellite site markers. Genome 2003, 46, 10-18. [CrossRef] [PubMed]

14. Vouillamoz, J.F.; McGovern, P.E.; Ergul, A.; Söylemezoglu, G.; Tevzadze, G.; Meredith, C.P.; Grando, M.S. Genetic characterization and relationships of traditional grape cultivars from Transcaucasia and Anatolia. Plant Genet. Resour. 2006, 4, 144-158. [CrossRef]

15. De Lorenzis, G.; Imazio, S.; Rusjan, D.; Vouillamoz, J.F.; Nikolaou, N.; Failla, O.; Scienza, A. Genetic investigation of grapevine varieties 'Ribolla Gialla' (Italy), 'Rebula' (Slovenia) and 'Robola' (Ionian Islands). Sci. Hortic. 2013, 150, 425-431. [CrossRef]

16. Žulj Mihalević, M.; Šimon, S.; Pejić, I.; Carka, F.; Sevo, R.; Kojic, A.; Gaši, F.; Tomić, L.; Jovanović Cvetković, T.; Maletić, E.; et al. Molecular characterization of old local grapevine varieties from South East European countries. Vitis 2013, 52, 69-76.

17. Merkouropoulos, G.; Michailidou, S.; Alifragkis, A.; Zioziou, E.; Koundouras, S.; Argiriou, A.; Nikolaou, N. A combined approach involving ampelographic description, berry oenological traits and molecular analysis to study native grapevine varieties of Greece. Vitis 2015, 54, 99-103.

18. Dong, Z.; Liu, W.; Li, X.; Tan, W.; Zhao, Q.; Wang, M.; Ren, R.; Ma, X.; Tang, X. Genetic relationships of 34 grapevine varieties and construction of molecular fingerprints by SSR markers. Biotechnol. Biotechnol. Equip. 2018, 32, 942-950. [CrossRef]

19. Popescu, C.F.; Crespan, M. Combining Microsatellite Markers and Ampelography for Better Management of Romanian Grapevine Germplasm Collections. Not. Sci. Biol. 2018, 10, 193-198. [CrossRef]

20. Mahmood, A.M.; Shaim, H.A.; Shabaq, M.H. Molecular characterization of autochthonous grapevine (Vitis vinifera L.) cultivars in Kurdistan using simple sequence repeats (SSRs). J. Univ. Garmian 2019, 6, 328-335. [CrossRef]

21. Taheri, F.; DarziRamandi, H. Microsatellite Markers Analysis for the Genetic Characterization and Relationships among Some of Iranian Local Grapevine Accessions (Vitis vinifera L.). Int. J. Fruit Sci. 2020, 20, 1-18. [CrossRef]

22. The Cooperation Programme INTERREG V-A “Greece-Bulgaria 2014-2020". Available online: http: //www.greece-bulgaria.eu/com/4_A-few-words-about-our-Programme (accessed on 13 April 2020).

23. Toonen, R.J.; Hughes, S. Increased throughput for fragment analysis on an ABI Prism 377 automated sequencer using a membrane comb and STRand software. Biotechniques 2001, 31, 1320-1324.

24. Drábek, J.; Smolíková, M.; Kalendar, R.A.; Lopes Pinto, F.; Pavlouŝek, P.; Klepárník, K.; Frébort, I. Design and validation of an STR hexaplex assay for DNA profiling of grapevine cultivars. Electrophoresis 2016, 37, 3059-3067. [CrossRef]

25. Sefc, K.; Regner, F.; Glössl, J.; Steinkellner, H. Identification of microsatellite sequences in Vitis riparia and their applicability for genotyping of different Vitis species. Genome 1999, 42, 367-373. [CrossRef] [PubMed]

26. Weir, B.S.; Cockerham, C.C. Estimating F-statistics for the analysis of population structure. Evolution 1984, $37,1358-1370$. 
27. Goudet, J. FSTAT (Version 1.2): A computer program to calculate F-statistics. J. Hered. 1995, 86, $485-486$. [CrossRef]

28. Belkhir, K.; Borsa, P.; Chikhi, L.; Raufaste, N.; Bonhomme, F. GENETIX 4.05, Logiciel Sous Windows TM Pour la Génétique des Populations. Laboratoire Genome; Populations, Interactions, CNRS UMR 5000, Universite' de Montpellier II: Montpellier, France, 2004.

29. Takezaki, N.; Nei, M.; Tamura, K. POPTREEW: Web version of POPTREE for constructing population trees from allele frequency data and computing some other quantities. Mol. Biol. Evol. 2004, 31, 1622-1624. [CrossRef]

30. Nei, M. Estimation of average heterozygosity and genetic distance from a small number of individuals. Genetics 1978, 89, 583-590.

31. Sefc, K.M.; Lopes, M.S.; Lefort, F.; Botta, R.; Roubelakis-Angelakis, K.A.; Ibáñez, J.; Peji'c, I.; Wagner, H.W.; Glössl, J.; Steinkellner, H. Microsatellite variability in grapevine cultivars from different European regions and evaluation of assignment testing to assess the geographic origin of cultivars. Theor. Appl. Genet. 2000, 100, 498-505. [CrossRef]

32. Biniari, K.; Stavrakaki, M. Genetic study of native grapevine varieties of northern, western and central Greece with the use of ampelographic and molecular methods. Not. Bot. Horti. Agrobo. 2019, 47, 46-53. [CrossRef]

33. Stavrakaki, M.; Biniari, K. Ampelographic and genetic characterization of grapevine varieties (Vitis vinifera L.) of the 'Mavroudia' group cultivated in Greece. Not. Bot. Horti. Agrobo. 2017, 45, 525-531. [CrossRef]

(C) 2020 by the authors. Licensee MDPI, Basel, Switzerland. This article is an open access article distributed under the terms and conditions of the Creative Commons Attribution (CC BY) license (http://creativecommons.org/licenses/by/4.0/). 